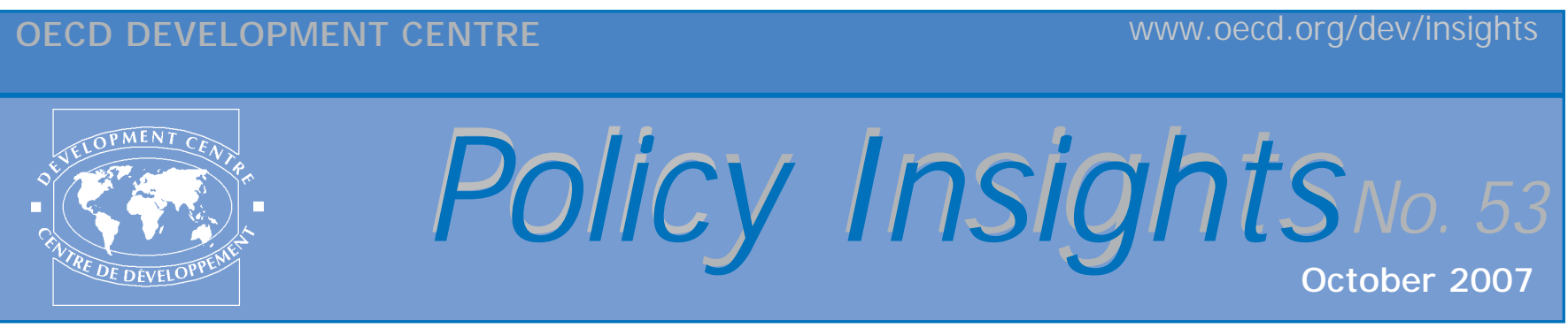

\title{
Latin America's Asian Opportunity
}

\section{(based on the Latin American Economic Outlook 2008)}

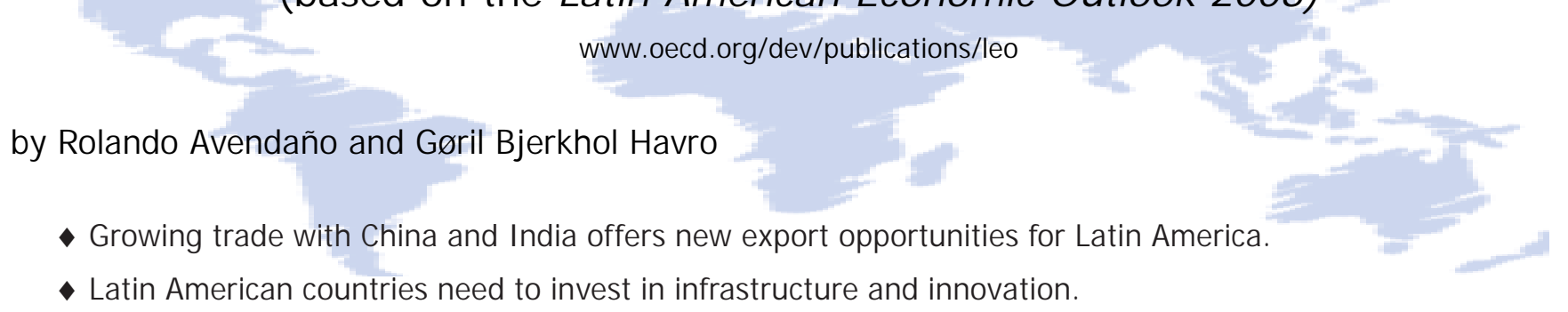

Between 1992 and 2002, Mexican exports almost doubled their market share in the United States, the country's main export destination. Since then, market share has decreased by nearly 10 per cent. At the same time, Mexico's comparative advantage in manufacturing has been diminishing, leading some to fear that the export model itself is at risk.

Latin America lacks infrastructure, and this explains some of Mexico's problems. Further down the continent, only 5 per cent of Brazilian roads are paved and both railroad and fluvial systems are underdeveloped. Port efficiency differs drastically across the region, and most ports are dramatically surpassed by those of Hong Kong, China and Singapore.

These handicaps may have mattered less in the past but the rise of China, and its competitive exports, represents a new challenge. Some concern is certainly justified. Mexico's annual export growth rate would have been 3 percentage points higher in the early 2000s, if Chinese export capabilities had remained unchanged.

Yet, for most Latin American countries, growth in Asia primarily represents an opportunity. The latest Latin American Outlook from the OECD Development Centre looks at 34 countries and shows that for the most part, Latin American economies are much less exposed to Chinese competition than are other emerging economies. This also applies to India. In both cases, Paraguay, Chile, Venezuela and Bolivia figure among the countries least exposed to competition, which is no surprise, since these are exporters of natural resources. Mexico's exports are similar to those of China, which is why it is likely to face a greater challenge. Somewhere in the middle are Brazil, Argentina and Colombia both in relation to China and to India.

Despite the visibility of raw-materials exports, the trade opportunities for Latin America are not limited to commodities. Both the Asian giants have growing domestic markets for Latin American exports, not all of them being exploited. Mexico exports telecommunications and electrical circuit equipment, sectors where China's and India's imports are also high, but where little trade is currently taking place. Argentina, Brazil, Chile and Uruguay all have established agricultural industries with expansion potential. Exploiting these opportunities, however, involves ensuring the necessary investments in infrastructure and innovation, and avoiding excessive specialisation in the commodity sectors.

A comparison of trade patterns between 2000 and 2005 suggests that Latin American comparative advantage in soft commodities (grains, sugar) and hard commodities (metals, oil) has increased. Manufacturing sectors have weakened, overall, as exemplified by the Mexican case, while in Venezuela, Ecuador, Bolivia and Chile, product concentration in exports has increased substantially (see figure). This specialisation can have negative effects on the other sectors of the economy, so-called "Dutch disease", unless it is managed by responsible macroeconomic policies and well-functioning institutions.

Export concentration by product

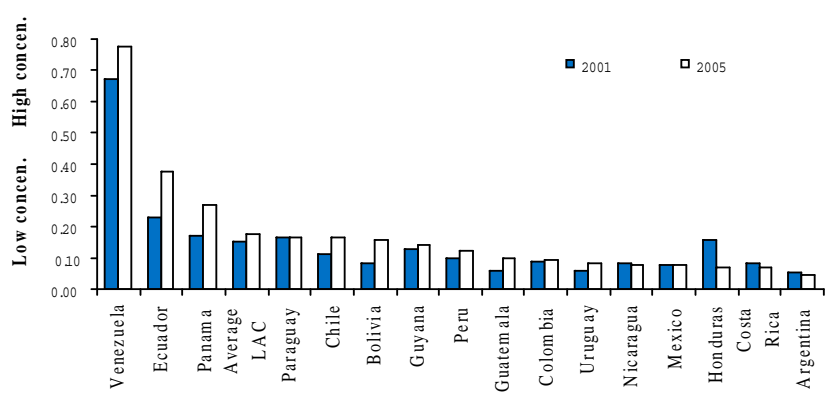

Source: OECD Development Centre (2007); Based on WITS and Comtrade data (2007) 
The growth of the Chinese and Indian economies and their increased participation in international trade has brought into sharp relief the need for Latin American countries to invest in infrastructure and innovation for the noncommodity sectors to prosper. For countries facing export competition, such as Mexico, it is important and urgent to build infrastructure that will enable efficient trade. In sectors and products where distance and time are key competitive assets, the urgency is acute if exporters are to continue to capitalise on their extraordinary geographical advantage.

Innovation is the key to long-term, diversified growth, and Latin American countries need to be in the forefront. Chile has proven to have an effective strategy in this area. In the last three decades the share of minerals in total exports has halved, although copper is still a significant export. Together with the fiscal discipline required to acquire a certain commodity independence, governments in Santiago have consistently focused on innovation, allowing other industries to develop, including wine, fresh fruit and salmon. Moreover, the example of Fundación Chile, one of the frontrunners in innovation partnerships, illustrates the achievements in technological transfer that can occur in certain industries. Elsewhere, countries like Brazil, have started to focus on potential synergies between science and technology promotion, $R \& D$ support and trade competitiveness.

Strong commodity demand is clearly driving the profitable relationship between the Asian giants and most of Latin America, but strategies to deal with the aftermath of the boom are urgently needed. Where commodities are not the driving force, or not the only one, competitiveness could be at risk from complacency and lack of attention to infrastructures and innovation. In the end, both groups of countries are in the same boat: without better infrastructures and enhanced innovation initiatives, the continent risks running off course.

When there is so much to gain, that would be a shame. 